Editorial

\title{
Contrast-Induced Nephropathy in Neurological Patients: A Crying Need for Prospective Randomized Controlled Trials
}

\author{
Parmod K. Bithal ${ }^{1}$ \\ ${ }^{1}$ Division of Neuroanesthesia, Department of Anesthesiology and \\ OR Administration, King Fahad Medical City, Riyadh, Saudi Arabia
}

J Neuroanaesthesiol Crit Care 2019;6:1-2

Contrast-induced nephropathy (CIN) is defined as an acute decrease in renal function after intravascular administration of iodinated contrast media (CM) in absence of other direct causes. Physicians working in critical care wards are very much familiar with this entity. It increases the burden on hospital resources. ${ }^{1}$ In addition, it has been linked to increased length of hospital stay and long-term mortality. ${ }^{2,3}$ It is the third leading cause of hospital-acquired acute kidney injury. ${ }^{4}$ Although its incidence in most studies has been found to be low (1 to $2 \%$ ) in general patient population, in high-risk patients it has been calculated to be more than 20 to $30 \%{ }^{5}$

Various interventional neuroradiological procedures (e.g., carotid artery stenting [CAS], carotid angioplasty, carotid angiogram, and embolization of vascular lesions) have made substantial advancement in the past couple of decades. All these procedures expose neurologically sick patients to iodinated radiocontrast media. Many of these patients are elderly with associated comorbidities. The vessels are imaged with iodinated contrast that has not only deleterious hemodynamic effects but is also injurious to the renal tubular cells mainly in the outer medulla. ${ }^{6}$ Although literature is replete with epidemiology of CIN in percutaneous coronary intervention, not much is published of the risks of CIN in patients undergoing interventional procedures for neurological conditions. More importantly, there are scant reports on prospective controlled data for neurointerventional field. Neuroradiological procedures differ from cardiac radiology endovascular procedures in respect of $\mathrm{CM}$ dose, injection technique, types of patients, and moreover, they are not on antiedema therapy.

Several risk factors that predispose a patient to CIN have been described, including chronic kidney disease, diabetes mellitus, hypertension, old age, use of nephrotoxic medications, such as nonsteroidal anti-inflammatory drugs, dehydration, large contrast volume, and repeated exposure to CM within 72 hours. ${ }^{2,7,8}$ Many neurological patients of stroke, CAS, and even aneurysmal subarachnoid hemorrhage patients fall in this high-risk category. In addition to the aforementioned risk factors, certain risk factors are unique to this patient population such as mannitol administration. Although potential renal protective properties of mannitol given after CM administration have been discussed in literature, they were not confirmed by Solomon et $\mathrm{al}^{9}$ who observed higher rate of CIN after the administration of saline and mannitol, as compared to saline alone. Additionally, the general beneficial role of mannitol in neurosurgical patients came under a cloud, when it was found to be an independent risk factor for acute kidney injury after cerebral trauma. ${ }^{10}$ Secondly, with mannitol administration, the volume of the infused fluid for hydration could be insufficient to prevent patients from post-contrast nephropathy. Therefore, mannitol is not recommended before or following contrast administration.

Kato et $\mathrm{al}^{11}$ observed $8.8 \%$ incidence of $\mathrm{CIN}$ in patients undergoing CAS. In the group that developed CIN, prolonged carotid sinus reflex (CSR) during the procedure was found to be in $57.1 \%$ of the cases. Neither preoperative renal function contrast volume nor history was related to the incidence of CIN, while on multivariate analysis, prolonged CSR was found to be an independent risk factor for CIN. Hemodynamic depression after CAS and carotid endarterectomy is caused by the manipulation of carotid sinus, leading to development of CIN in this group of patients. The frequency of development of prolonged CSR during CAS implantation varies from 11 to $42 \%{ }^{12}$ Donahue et $\mathrm{al}^{13}$ too observed that in the presence of pre-existing chronic kidney disease, persistent hemodynamic depression (decrease in systolic pressure below $90 \mathrm{~mm} \mathrm{Hg}$ or mean arterial pressure below $60 \mathrm{~mm} \mathrm{Hg}$ ) was more common in patients who developed acute kidney injury, and only a brief episode of $2.5 \mathrm{~min}$ of hypotension was the threshold of hemodynamic depression. Thus, according to

\footnotetext{
Address for correspondence Parmod K. Bithal, MD, Division of Neuroanesthesia, Department of Anesthesiology and OR Administration, King Fahad Medical City, Riyadh, Saudi Arabia

(e-mail: bithal.parmod@gmail.com).
}

DOI https://doi.org/ 10.1055/s-0039-1679196 ISSN 2348-0548.
Copyright @2019 Indian Society of Neuroanaesthesiology and Critical Care

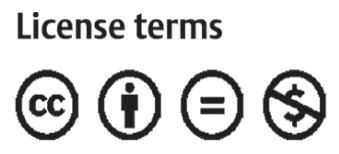


them, hemodynamic depression and not the contrast volume represents an independent predictor of acute kidney injury.

Tao et al observed increasing age, proteinuria, estimated glomerular filtration rate of less than $60 \mathrm{~mL} / \mathrm{min} / 1.73 \mathrm{M},{ }^{2}$ high National Institutes of Health Stroke Scale score and anemia to be independent risk factors for CIN in patients with stroke undergoing cerebral angiography with or without CAS implantation. In their study, multivariate regression analysis revealed that even after adjusting for potential confounding risk factors, patients with proteinuria still had fivefold higher risk of CIN than patients without. However, some established factors for CIN in coronary angiography, such as age and diabetes, were not seen as risk factors in this study owing to lower proportion of elderly and patients with diabetes mellitus. ${ }^{14}$ However, various nonrandomized evidence suggests that computed tomography (CT) angiogram and CT perfusion studies are not associated with statistically significant increase in risk of acute kidney injury in patients of stroke, even those with chronic kidney disease. ${ }^{15}$

Aneurysmal subarachnoid hemorrhage (aSAH) patients require multiple contrast studies for carotid angiogram and coil embolization. Lee et al identified contrast-induced acute kidney injury in 7.3\% patients undergoing coil embolization. They remarked CIN to be an independent predictor of the overall outcome of aSAH after endovascular treatment.. ${ }^{16}$ Furthermore, they also evaluated the impact of GCS on CIN in aSAH patients and concluded that it was the low initial GCS that was responsible for the CIN in them without the negative influence of other factors (e.g., volume of contrast, type of contrast, duration of procedure and size of aneurysm, age, and diabetes mellitus). However, Prasad et al ${ }^{17}$ observed that CIN in these patients may be the result of administration of large volume of $\mathrm{CM}(>250 \mathrm{~mL})$. Although the direct association between $\mathrm{CIN}$ and contrast agent usage has not been proven, reducing the total amount of $\mathrm{CM}$ used in the diagnosis and treatment of aSAH is important. However, some authors claim that only age more than 75 years is a predisposing factor for CIN development in this neurological condition. ${ }^{18}$

A plethora of therapies for the prevention of CIN have been suggested of which, the most beneficial is good hydration of the patient with normal saline. ${ }^{19}$ Volume expansion maintains satisfactory blood pressure, good renal blood flow, and nitric oxide production. All these factors prevent medullary ischemia and enhance contrast excretion.

Though most of the studies do not conclude that the incidence of CIN as well as factors leading to occurrence of CIN is different in neurologically sick patients compared with non-neurological patients, probably additional unique factors do play a role in etiology in them. Clearly, our knowledge in this context is limited owing to lack of large, high-quality, multicenter randomized controlled trials. Until we have results from such trials, we have to accept the observations from retrospective data, albeit, with a pinch of salt.

\section{References}

1 McCullough PA, Wolyn R, Rocher LL, Levin RN, O'Neill WW. Acute renal failure after coronary intervention: incidence, risk factors, and relationship to mortality. Am J Med 1997;103(5):368-375

2 Rihal CS, Textor SC, Grill DE, et al. Incidence and prognostic importance of acute renal failure after percutaneous coronary intervention. Circulation 2002;105(19):2259-2264

3 Levy EM, Viscoli CM, Horwitz RI. The effect of acute renal failure on mortality. A cohort analysis. JAMA 1996; 275(19):1489-1494

4 Nash K, Hafeez A, Hou S. Hospital-acquired renal insufficiency. Am J Kidney Dis 2002;39(5):930-936

5 Gleeson TG, Bulugahapitiya S. Contrast-induced nephropathy. AJR Am J Roentgenol 2004;183(6):1673-1689

6 McCullough PA, Young A, Shutze WP. Acute kidney injury following carotid artery stenting. JACC Cardiovasc Interv 2015;8(11):1515-1517

7 Taliercio CP, Vlietstra RE, Fisher LD, Burnett JC. Risks for renal dysfunction with cardiac angiography. Ann Intern Med 1986;104(4):501-504

8 Freeman RV, O’Donnell M, Share D, et al; Blue Cross-Blue Shield of Michigan Cardiovascular Consortium (BMC2). Nephropathy requiring dialysis after percutaneous coronary intervention and the critical role of an adjusted contrast dose. Am J Cardiol 2002;90(10):1068-1073

9 Solomon R, Werner C, Mann D, D'Elia J, Silva P. Effects of saline, mannitol, and furosemide on acute decreases in renal function induced by radiocontrast agents. $\mathrm{N}$ Engl J Med 1994;331(21):1416-1420

10 Fang L, You H, Chen B, et al. Mannitol is an independent risk factor of acute kidney injury after cerebral trauma: a casecontrol study. Ren Fail 2010;32(6):673-679

11 Kato T, Sakai H, Tsujimoto M, Nishimura Y. Prolonged carotid sinus reflex is a risk factor for contrast-induced nephropathy following carotid artery stenting. Am J Neuroradiol 2011;32(3):441-445

12 Dangas G, Laird JR Jr, Satler LF, et al. Postprocedural hypotension after carotid artery stent placement: predictors and short- and long-term clinical outcomes. Radiology 2000;215(3):677-683

13 Donahue M, Visconti G, Focaccio A, et al. Acute kidney injury in patients with chronic kidney disease undergoing carotid artery stent implant. JACC Cardiovasc Interv 2015;8(11):1506-1514

14 Tao Y, Dong W, Li Z, et al. Proteinuria as an independent risk factor for contrast-induced acute kidney injury and mortality in patients with stroke undergoing cerebral angiography. J Neurointerv Surg 2017;9(5):445-448

15 Brinjikji W, Demchuk AM, Murad MH, et al. Nephrons over neurons. A systematic review and meta-analysis of contrast induced nephropathy in patients with acute stroke. Stroke 2017;48(7):1862-1868

16 Lee HG, Kim WK, Yeon JY, et al. Contrast induced acute kidney injury after coil embolization for aneurysmal subarachnoid hemorrhage. Yonsei Med J 2018;59(1):107-112

17 Prasad V, Gandhi D, Stokum C, Miller T, Jindal G. Incidence of contrast material-induced nephropathy after neuroendovascular procedures. Radiology 2014;273(3):853-858

18 Ray B, Rickert KL, Welch BG, et al. Development of contrastinduced nephropathy in subarachnoid hemorrhage: a single center perspective. Neurocrit Care 2013;19(2):150-156

19 Mueller C. Prevention of contrast-induced nephropathy with volume supplementation. Kidney Int Suppl 2006; 100(100):S16-S19

Conflict of Interest

None declared. 